\title{
Further Observations on the Association of the Colicine V Plasmid of Escherichia coli with Pathogenicity and with Survival in the Alimentary Tract
}

\author{
By H. WILliAMS SMITH AND M. B. HUGGINS \\ Houghton Poultry Research Station, Houghton, \\ Huntingdon PE⿺ $72 D A$, Cambridgeshire
}

(Received 7 July 1975; revised 4 September 1975)

\begin{abstract}
S UMMARY
A high proportion of invasive strains of Escherichia coli produced colicine V. This property was easily eliminated from 20 of $2 \mathrm{I}$ of these strains by 'curing' agents, especially sodium lauryl sulphate, indicating that the genes determining it were located on a plasmid (ColV) which was transmitted from ten of the strains by conjugation. Inoculated intramuscularly, the $\mathrm{ColV}^{-}$forms of all $\mathrm{I} 7$ strains tested were less pathogenic for chickens than the corresponding ColV + forms. The pathogenicity of the ColV- forms of four strains was increased, usually to that of the $\mathrm{ColV}^{+}$form from which they were derived, by implanting other ColV determinants in them. Much higher concentrations of organisms were found in the blood and liver of chickens infected with $\mathrm{ColV}^{+}$forms than in chickens infected with $\mathrm{ColV}^{-}$forms. Inoculated intraperitoneally, the $\mathrm{ColV}^{+}$form of one of the strains, BI88, was more pathogenic for mice than the ColV- form; much higher concentrations of organisms were found in the peritoneal fluid and blood of $\mathrm{ColV}^{+}$-inoculated mice than of $\mathrm{ColV}^{-}$-inoculated mice. Inoculated orally and intravenously, ColV ${ }^{+}$forms were more pathogenic for colostrum-deprived calves than the corresponding ColV ${ }^{-}$forms. After mixtures of $\mathrm{ColV}^{+}$and $\mathrm{ColV}^{-}$organisms of the same strain in ratios of $1: 10,1: 100$ or $1: 1000$ were given orally, they were found in a similar ratio in the contents of the alimentary tract $\mathrm{I}$ to 2 days later, when the calves were near to death. Many more $\mathrm{ColV}^{+}$than $\mathrm{ColV}^{-}$organisms were found in the mesenteric lymph nodes, the deeper tissues and the blood; in the urinary and gall bladders, locations remote from the defence mechanisms of the body, the numbers of ColV ${ }^{-}$organisms sometimes exceeded those of ColV ${ }^{+}$ organisms. Colicine $\mathrm{V}$, although demonstrated in the blood at death, did not appear adversely to influence the concentration of $\mathrm{ColV}^{-}$organisms in these calves.

Several days after mixtures of ColV ${ }^{+}$and $\mathrm{ColV}^{-}$organisms of strain BI 88 were taken orally by two human beings, the $\mathrm{ColV}^{+}$organisms became much more numerous in their faeces than the ColV ${ }^{-}$ones. Similar results were obtained when $c o l \mathrm{Vr}^{\mathrm{r}}$ organisms of BI 88 were included in the inoculum or when a strain whose $\mathrm{ColV}^{-}$form was completely colicine V-resistant was studied.

$\mathrm{A} \mathrm{ColE}^{+}$form of BI $88 \mathrm{ColV}^{-}$was no more pathogenic for chickens, mice or colostrum-deprived calves than was a $\mathrm{ColE}^{-}$form of this strain, and it did not persist in the faeces of the two human beings for longer than the $\mathrm{ColE}^{-}$form.
\end{abstract}

\section{INTRODUCTION}

In a recent study (Smith, I974), plasmids determining colicine V production were transterred trom a variety of wild-type strains of Escherichia coli to laboratory strains of this organism. As a result, the laboratory strains became more pathogenic for experimental anımals, the increased pathogenicity being associated with a greater ability of the ColV ${ }^{+}$ 
forms of these strains to resist the defence mechanisms of the host. Principally because the increased pathogenicity of the strains could not be separated by laboratory procedures from their colicine $V$ production, it was tentatively concluded that either the genes determining each of these properties were located on the same plasmid or colicine $\mathrm{V}$ itself was responsible for the increased pathogenicity.

The subsequent finding that 'curing' agents eliminated ColV from organisms of invasive strains of E. coli (Smith and Huggins, unpublished work) presented an opportunity to obtain more information on the relationship of colicine $\mathrm{V}$ to pathogenicity. It seemed important to do this, because the fact that ColV bestows increased pathogenicity on the laboratory strains of $E$. coli does not necessarily imply that it does so in invasive strains of $E$. coli or that it plays any part in the pathogenesis of disease caused by these strains. The laboratory strains (including $E$. coli $\mathrm{KI} 2$ ) used in previous experiments were not regarded as natural pathogens, and large doses had to be injected, usually intravenously, into experimental animals to cause death. By contrast, invasive strains usually produce death in much lower dosage and by more natural routes of infection, including the oral route in colostrumdeprived calves, and with lesions resembling those present in the natural disease. The results of these observations are reported, as are others on the ability of $\mathrm{ColV}^{+}$and $\mathrm{ColV}^{-}$organisms of the same strain to survive in the alimentary tract.

\section{METHODS}

Only the methods not described by Smith (1974) are dealt with here.

Experimental animals. Male calves from three Jersey herds were brought to the laboratory 3 to $12 \mathrm{~h}$ after birth and immediately used in experiments; the immune-globulin-negative status of the serum of the colostrum-deprived ones was confirmed by the zinc sulphate flocculation test (Aschaffenburg, I949). They were given I 1 heat-sterilized cows' milk twice daily. Chickens used to study the survival of $E$. coli in the alimentary tract were six weeks old; those used in all other experiments were four weeks old.

E. coli strains. Apart from $\mathrm{KI} 2$, all the strains had been isolated from the blood or internal organs of human beings (prefix H), calves (prefix B), lambs (prefix s) or chickens (prefix F) suffering from bacteraemia.

Culture media and cultural conditions. Except where stated, all media were incubated at $37^{\circ} \mathrm{C}$ for $24 \mathrm{~h}$. Broth cultures consisted of organisms grown in $10 \mathrm{ml}$ nutrient broth, Oxoid No. 2 (CM67), in a shaking water bath, and contained approximately Io $^{9}$ viable organisms $/ \mathrm{ml}$. Only in mating experiments were broth cultures not shaken. The broth was not suitable for colicine $\mathrm{V}$ production. The nutrient agar employed was Difco tryptose agar (B64) and the MacConkey's agar was Oxoid ( $\left.\mathrm{CM}_{7}\right)$. Synthetic medium consisted of $(\mathrm{g} / \mathrm{l})$ : $\mathrm{K}_{2} \mathrm{HPO}_{4}, 7 ; \mathrm{KH}_{2} \mathrm{PO}_{4}, 3 ;\left(\mathrm{NH}_{4}\right)_{2} \mathrm{SO}_{4}, \mathrm{I} ; \mathrm{MgSO}_{4} \cdot 7 \mathrm{H}_{2} \mathrm{O}, 0 \cdot \mathrm{I} ; \mathrm{NaCl}, 5$; glucose, 5; agar, I 5 . Colicine $\mathrm{V}$-containing plates were plates of nutrient agar whose entire surface had been inoculated with a broth culture of a ColV $+E$. coli strain, incubated and then maintained at $60{ }^{\circ} \mathrm{C}$ for $\mathrm{I}$ h to kill the E. coli; a thin layer of nutrient agar was then poured over their surface.

Demonstration of ColV transmissibility in E. coli strains. Strains that produced colicine V were grown in broth with a nalidixic acid-resistant mutant (nal-r) of a lac ${ }^{-}$E. coli $\mathrm{Kr} 2$ strain. The mixed cultures were inoculated on to colicine V-containing plates that had been overlaid with nutrient agar containing $30 \mu \mathrm{g}$ sodium nalidixate $/ \mathrm{ml}$. Colonies that grew after incubation were then checked to confirm that they were of $\mathrm{ColV}^{+} E$. coli $\mathrm{KI} 2$ organisms. Using antibiotic resistance determinants as markers, transfer factors F (Lederberg, Cavalli 
\& Lederberg, I 952; Hayes, I953) and I [I $=$ IdrdI6(I); Hardy et al. 1973] were implanted in those strains whose colicine $\mathrm{V}$ production was not shown to be transmissible, and the strains were then re-examined.

Preparation of colicine V-resistant mutants $(\mathrm{col} V \mathrm{~V})$ of E. coli strains. Colicine V-containing plates were inoculated heavily with broth cultures of strains from which it was desired to isolate col $\mathrm{V}^{\mathrm{r}}$ mutants and incubated. Colonies that grew were purified and checked for resistance to colicine $\mathrm{V}$.

Elimination of ColV from E. coli strains. The sodium lauryl sulphate method of Tomoeda et al. (1968), the acridine orange method of Hirota (I960) and the ethidium bromide method of Bouanchaud, Scavizzi \& Chabbert (1968) were employed. Strains were transferred several times in broth containing these agents if success did not follow the first transfer. Unless stated, any culture of an invasive strain referred to below as ColV- was obtained by sodium lauryl sulphate treatment; a culture of the same strain referred to as $\mathrm{ColV}^{+}$was a ColV + isolate from the same transfer in sodium lauryl sulphate as that in which the $\mathrm{ColV}^{-}$culture was obtained, i.e. it was not the original $\mathrm{ColV}^{+}$strain before sodium lauryl sulphate treatment.

The re-introduction of ColV into Col $V^{-}$forms of $E$. coli. The ColV- forms were grown in broth with an auxotrophic ColV ${ }^{+} \mathrm{Tet}^{+} \mathrm{I}^{+}$strain of $E$. coli $\mathrm{KI} 2$ (Tet $=$ tetracycline resistance determinant) and the mixed culture then inoculated on to plates of synthetic medium containing $20 \mu \mathrm{g}$ tetracycline $/ \mathrm{ml}$. Colonies that grew on this medium were tested to find ones that were $\mathrm{ColV}^{+}$. In one case, the ColV $\mathrm{C}^{+} \mathrm{K} / 2$ donor strain employed possessed the transfer factor of an invasive strain instead of $\mathrm{I}$.

Differentiation of $\mathrm{ColV}^{+}, \mathrm{ColV}^{-}$and colV $\mathrm{V}^{\mathrm{r}}$ colonies from each other. Colonies from plates of MacConkey's agar that had been inoculated with material containing ColV ${ }^{+}, \mathrm{ColV}^{-}$ and $c o l \mathrm{Vr}^{\mathrm{r}}$ organisms of the same $E$. coli strain were spot-inoculated on to nutrient agar plates spread with a broth culture of $E$. coli $\mathrm{KI} 2$ to differentiate the ColV $\mathrm{V}^{+}$colonies from the $\mathrm{ColV}^{-}$and $c o l \mathrm{~V}^{\mathrm{r}}$ ones. Those found not to produce colicine were then inoculated over small areas of a colicine $\mathrm{V}$-containing plate to differentiate the $\mathrm{ColV}^{-}$ones from the $\mathrm{col}^{\mathrm{V}} \mathrm{V}^{\mathrm{r}}$ ones.

Determination of colicine $V$ in cultures, body fluids and tissues. These were centrifuged to remove solid matter and most of the bacteria they contained and then heated to $60{ }^{\circ} \mathrm{C}$ for I h, a procedure that had no effect on their colicine $V$ content. Tissues such as muscle were first ground in a pestle and mortar with the smallest amount of broth necessary to form a thick suspension. Successive twofold dilutions were prepared from the heated fluids and $0.03 \mathrm{ml}$ of each spotted on to the surface of a plate of nutrient agar over which a lawn of a diluted broth culture of $E$. coli KI 2 had been spread. The plates were incubated and the highest dilution that prevented bacterial growth was recorded as the titre.

The survival of $\mathrm{ColV}^{+}, \mathrm{ColE}^{+}$and ColV organisms in the alimentary tract of chickens or human beings. Groups of chickens were given orally $5 \times \mathrm{IO}^{9}$ viable $\mathrm{ColV}^{+}$or $\mathrm{ColV}^{-}$organisms of the same nal-r spc-r strain of E. coli (spc = spectinomycin). Six days later they were killed; the total E. coli in their caecal contents was estimated by counting on MacConkey's medium, and the number of inoculated $E$. coli estimated by counting on this medium, containing $20 \mu \mathrm{g}$ each of spectinomycin and sodium nalidixate $/ \mathrm{ml}$. Mixtures of $\mathrm{ColV}^{+}$, $\mathrm{ColV}^{-}$and colvr; of $\mathrm{ColV}^{+}$and $\mathrm{ColV}^{-}$; or of $\mathrm{ColE}^{+}$and $\mathrm{ColE}^{-}$organisms of the same $n a l-r$ str-r or nal-r spc-r strain of $E$. coli were taken orally by two human beings (str = streptomycin). Their faeces were cultured at intervals on MacConkey's agar containing, per $\mathrm{ml}, 20 \mu \mathrm{g}$ of each of the antibiotics to which the inoculated organisms were resistant. Colonies that grew were then classified according to their colicine status. On some occasions 
the total number of viable $E$. coli in the faeces was estimated by counting on MacConkey's agar and the number of inoculated $E$. coli by counting on antibiotic-containing MacConkey's medium.

Preparation of ColE $\mathrm{C}^{+}$and $\mathrm{ColE}^{-}$forms of E. coli $\mathrm{BI} 88 \mathrm{ColV}^{-}$. $\mathrm{A} \mathrm{ColE}_{1}{ }^{+} \mathrm{Tet}^{+} \mathrm{F}^{+}$strain of $E$. coli $\mathrm{KI}$, in which Tet and $\mathrm{F}$ but not ColE were linked, was mated with a nal-r str-r mutant of $\mathrm{BI} 88 \mathrm{ColV}^{-}$, and a $\mathrm{ColE}^{+} \mathrm{Tet}^{+} \mathrm{F}^{+}$and a ColE${ }^{-} \mathrm{Tet}^{+} \mathrm{F}^{+}$segregant of $\mathrm{BI} 88$ selected. The segregants were then treated with sodium lauryl sulphate to remove Tet and F.

\section{RESULTS}

Prevalence of the ColV $V^{+}$form in invasive strains of E. coli

Epidemiologically-unrelated strains, most of which had been maintained in the laboratory for several years, were tested for colicine V production. Examination of serotype $\mathrm{O}_{7} 8: \mathrm{K} 80$ cultures showed that 25 of 3 I cattle strains, 3 of 5 sheep strains and 36 of 44 chicken strains were positive. Of 54 chicken strains belonging to serotype $\mathrm{O}_{2}$ : $\mathrm{KI}, 40$ were positive. Examination of miscellaneous untyped cultures showed that 50 of 68 chicken strains and 10 of 45 human strains were positive.

\section{The nature of the ColV determinant in invasive strains of $E$. coli}

Twenty-one invasive strains of $E$. coli, of human, bovine, ovine and avian origin and belonging to several different antigenic types, were tested for their ability to mobilize a streptomycin/sulphonamide resistance determinant in a $\mathrm{Tra}^{-} E$. coli $\mathrm{KI} 2$ strain. The examination revealed that ten possessed transfer factors $\left(\mathrm{Tra}^{+}\right)$and transmitted their ColV determinants, four were $\mathrm{Tra}^{+}$but did not transmit their ColV determinants, and seven were $\mathrm{Tra}^{-}$; the determinants in the strains belonging to the last category could not be mobilized by implanting transfer factors F or I in them. Strains of serotype $\mathrm{O}_{78}$ : K80 were found in all three categories. Escherichia coli K12 that had acquired ColV from five of the ten strains in which it was transmissible became fully susceptible to the MS2 phage, indicating that the transfer factors in these five strains were F-like. In general, ColV- forms were obtained more easily by sodium lauryl sulphate treatment from these ten than from the other eleven; from only one strain were they not obtained by this method, even after four transfers. Forms that had lost ColV were also obtained from three of eight strains by acridine orange treatment and from one of five by ethidium bromide treatment. An occasional $\mathrm{ColV}^{-}$form was obtained from six of the 2I strains during four transfers in plain nutrient broth. The ColV-- forms of six of the 2I strains were resistant to colicine V, but the remainder were susceptible, though less sensitive than E. coli KI2.

\section{The effect of growing ColV $V^{+}$and $\mathrm{ColV}^{-}$forms of the same strain together in broth}

Nutrient broth was inoculated with approximately equal amounts of $\mathrm{ColV}^{+}$and $\mathrm{ColV}^{-}$ organisms of one or other of eleven invasive E. coli strains and incubated. The ColV status of 50 or 100 colonies obtained from each of the eleven mixed cultures at 0 and $24 \mathrm{~h}$ was determined. The total number examined at each occasion was 800 . Of those examined at $\mathrm{O}$ and $24 \mathrm{~h}, 365$ and 294, respectively, were ColV ${ }^{+}$. In only two mixed cultures had the proportion of $\mathrm{ColV}^{+}$organisms increased during the $24 \mathrm{~h}$ incubation period and in neither of these was the increase statistically significant. Colicine $\mathrm{V}$ was not detected in any of the mixed cultures.

Two additional mixed cultures of $E$. coli BI 88 were studied. One contained ColV ${ }^{+}$, $\mathrm{ColV}^{-}$and colicine V-resistant mutant $\left(\mathrm{col} \mathrm{V}^{\mathrm{r}}\right)$ organisms, and the other contained $\mathrm{ColV}^{-}$ 
Table I. The lethality for chickens of different forms of

E. coli strain $\mathrm{F} 65$ given intramuscularly

\begin{tabular}{|c|c|c|c|c|}
\hline \multirow{2}{*}{$\begin{array}{l}10^{-6} \times \text { no. of viable organisms } \\
\text { inoculated }\end{array}$} & \multicolumn{4}{|c|}{ No. of chickens that died when given*: } \\
\hline & Colv'+ & Colv & $\mathrm{ColV}^{+}\left(\mathrm{V}^{-}\right)$ & $\mathrm{ColV}^{-}\left(\mathrm{V}^{-}\right)$ \\
\hline 300 & 10 & 9 & 8 & 10 \\
\hline 100 & 10 & o & 8 & 0 \\
\hline 30 & 8 & 0 & 8 & 0 \\
\hline IO & 8 & I & 6 & 0 \\
\hline 3 & 3 & 0 & 5 & 0 \\
\hline
\end{tabular}

* The ColV ${ }^{+}\left(\mathrm{V}^{-}\right)$form was the ColV - form in which ColV, Tet and transfer factor I were implanted; the ColV $-\left(V^{-}\right)$form was the ColV $V^{-}$form in which only Tet and I were implanted. Each form was given to ten chickens.

and $c o l \mathrm{~V}^{\mathrm{r}}$ organisms. In both cultures, the $\mathrm{ColV}^{-}$and the $c o l \mathrm{~V}^{r}$ organisms multiplied at the same rate.

Seven of the mixed culture experiments in which the ColV determinant of the ColV ${ }^{+}$ form was transmissible were repeated employing a nal-r mutant of the $\mathrm{ColV}^{-}$form. All of Ioo nal-r colonies isolated from each of the mixed cultures after incubation were ColV-. Thus it appeared that $\mathrm{ColV}^{-}$forms of invasive strains multiplied at approximately the same rate as the corresponding $\mathrm{ColV}^{+}$forms in broth, and that while doing so they had only a low probability of acquiring ColV.

\section{The pathogenicity of $\mathrm{ColV}^{+}$and $\mathrm{ColV}^{-}$forms of the same} invasive $E$. coli strain for chickens

Groups of ten chickens were injected intramuscularly (i.m.) with successive doses (each at one-third the concentration of the one before) of the following forms of E. coli 665 : the $\mathrm{ColV}^{+}$form, the $\mathrm{ColV}^{-}$form, the $\mathrm{ColV}^{-}$form into which a ColV determinant had been introduced with transfer factor I, and the ColV form into which only transfer factor I had been introduced (Table $\mathrm{r}$ ). The two ColV ${ }^{+}$forms were clearly more lethal than the two $\mathrm{ColV}^{-}$forms; they also produced severe lesions in many survivors, whereas the two $\mathrm{ColV}^{-}$ forms did so in only a few. Comparable results were obtained in substantially similar experiments with strains BI88, FI 85 and $\mathrm{H} 247$.

The macroscopic lesions found in chickens that died from infection with $\mathrm{ColV}^{+}$and $\mathrm{ColV}^{-}$forms of $\mathrm{F} 65$ and of other invasive strains of $E$. coli resembled those found in the natural disease. They consisted principally of a proliferative pericarditis, peritonitis and airsacculitis. Most deaths occurred two to four days after infection. They were uncommon after five days, although at seven days, when experiments were concluded, severe lesions were still present in some of the chickens.

Intramuscular pathogenicity tests with 13 further strains invariably gave clear evidence of the greater lethality of $\mathrm{ColV}^{+}$forms than $\mathrm{ColV}^{-}$forms. These experiments included two in which ColV had been removed by acridine orange treatment and one in which it had been lost during passage in broth.

Two groups of 47 chickens were also inoculated i.m. with organisms of either a ColE- or a ColE ${ }^{+}$form of a nal-r str-r strain of в $88 \mathrm{ColV}^{-}$. Nine of the chickens inoculated with the $\mathrm{ColE}^{+}$form and ten of the chickens inoculated with the ColE- form died. 


\section{The concentration of $\mathrm{ColV}^{+}$and $\mathrm{ColV}^{-}$organisms in the tissues of infected chickens}

Ten chickens were inoculated i.m. with $5 \times \mathrm{IO}^{8}$ viable $\mathrm{ColV}^{+}$organisms of the $\mathrm{Tra}^{-}$strain, BI88, and ten further birds were similarly treated with $\mathrm{ColV}^{-}$organisms. Slaughter and examination $24 \mathrm{~h}$ later revealed that the $\mathrm{ColV}^{+}$form was much more invasive than the $\mathrm{ColV}^{-}$. The median values of $\mathrm{ColV}^{+}$organisms in blood and ground tissue were $\left(\mathrm{IO}^{-6} \times\right.$ viable counts $/ \mathrm{ml}$, with ranges in parentheses): blood, 80 (9 to 600); liver, 30 ( 2 to 800 ); inoculated muscle, 5000 (3000 to 8000). The corresponding figures for ColV- organisms were: blood, 0.04 (0.0 I to 0.9$)$; liver, 0.5 (0.15 to 2 ); inoculated muscle, 2500 (1000 to 5000).

Four chickens died I to 3 days after inoculation into the breast muscle with the noncolicine $V$-transmitting strain BI 88 in a total dose of $5 \times 10^{8}$ viable organisms, consisting of $\mathrm{ColV}^{+}, \mathrm{ColV}^{-}$and $\mathrm{col}^{\mathrm{r}}$ forms in a ratio of $\mathrm{I}: 4 \cdot 5: 4 \cdot 5$. Practically all organisms isolated from liver and blood were ColV ${ }^{+}$. Examination of 50 organisms from the inoculated muscle of each of the four birds showed that $0.5,26.5$ and $73 \%$ of the total of 200 organisms consisted of $\mathrm{ColV}^{-}, \mathrm{col} \mathrm{V}^{\mathbf{r}}$ and $\mathrm{ColV}^{+}$forms respectively. No colicine $\mathrm{V}$ was detected in blood, liver or muscle.

An exactly similar inoculum was given to three further chickens, but in this instance the $\mathrm{ColV}^{+}$organisms were injected into the left leg muscle and the $\mathrm{ColV}^{-}$and $c o l \mathrm{~V}^{\mathrm{r}}$ forms into the right breast muscle. Death occurred in 2 to 3 days and liver, blood and leg muscle contained organisms that were almost exclusively $\mathrm{ColV}^{+}$. Breast muscle contained 53.5 and $3 \mathrm{r} \%$ of $\mathrm{ColV}^{+}$and $\mathrm{col} \mathrm{V}^{\mathrm{r}}$ forms, respectively, and a higher proportion of $\mathrm{ColV}^{-}$than in the previous experiment, namely $15.5 \%$.

Three more chickens that died after receiving a mixture of $\mathrm{ColV}^{-}$and $c o l \mathrm{~V}^{\mathrm{r}}$ organisms i.m. yielded the two forms from inoculated muscle, liver and blood in approximately the same proportions as in the inoculum.

Mixtures of ColV ${ }^{+}$and ColV- organisms of three invasive strains, B I92, FI85 and H26I, whose ColV- forms were completely resistant to colicine $\mathrm{V}$, were each inoculated i.m. into a chicken; the $\mathrm{ColV}^{+}: \mathrm{ColV}^{-}$ratio in the inocula was I :IO. All of 50 isolates obtained from the liver and from the blood of each of these three chickens after death were ColV ${ }^{+}$, and so were most from the inoculated muscle.

The pathogenicity for mice of $\mathrm{ColV}^{+}, \mathrm{ColV}^{-}$and $\mathrm{ColV}^{-} \mathrm{ColE}^{+}$organisms of E. coli $\mathrm{BI} 88$; the concentration of $\mathrm{ColV}^{+}$and $\mathrm{ColV}^{-}$organisms in the peritoneal fluid and blood of mice

When the $\mathrm{ColV}^{+}$form of strain $\mathrm{BI} 88$ was injected intraperitoneally (i.p.) into four groups of 25 mice at doses of $10^{8}, 10^{7}, 10^{6}$ and $10^{5}$ viable organisms, the deaths produced were 25,23, I 3 and 2, respectively. The corresponding results for a parallel virulence titration of the ColV- form were $\mathrm{I} 8$, o, o and o.

No difference in mouse lethality could be shown between the ColV- and the ColV $\mathrm{ColE}^{+}$ forms of the nal-r str-r mutant of strain BI 88; each form produced a single death in a group of 25 mice when the dose was $10^{7}$ viable organisms i.p., and $>20$ deaths when the dose was $10^{8}$.

$\mathrm{The}^{\mathrm{ColV}} \mathrm{V}^{+}$and $\mathrm{ColV}^{-}$forms of strain $\mathrm{BI} 88$ were each injected i.p. into ten mice in doses of $10^{7}$ viable organisms. After $24 \mathrm{~h}$, five mice given ColVt had just died and the other five were moribund; mice that received $\mathrm{ColV}^{-}$were apparently healthy. The survivors were killed and all mice were examined. The median values of the $\mathrm{ColV}^{+}$organisms in blood and 
Table 2. The concentration of E. coli organisms in the intestinal contents and tissues of colostrum-deprived calves given ColV' or ColV-and colV $\mathrm{V}^{\mathrm{r}}$ forms of E. coli $\mathrm{BI} 88$ orally

Calf $\mathrm{A}$ was given $\mathrm{ColV}^{+}$organisms and calves $\mathrm{B}$ and $\mathrm{C}$ were given a mixture of $\mathrm{ColV}^{-}$and $c o l \mathrm{~V}^{\mathrm{r}}$ organisms; the infecting dose for all three calves was $1 \cdot 5 \times 10^{10}$ viable organisms. Calves $\mathbf{A}$ and $\mathbf{B}$ were killed $24 \mathrm{~h}$ after infection and calf $\mathrm{C} 48 \mathrm{~h}$ after infection. The small intestine was sampled from three regions, No. I being nearest the stomach and No. 3 nearest the caecum; the lymph nodes associated with these regions were similarly identified.

Materials examined
Small intestinal contents 1
Small intestinal contents 2
Small intestinal contents 3
Caecal contents
Faeces
Retro-pharyngeal lymph node
Small intestinal lymph node I
Small intestinal lymph node 2
Small intestinal lymph node 3
Popliteal lymph node
Blood
Muscle
Lung
Spleen
Liver
Bile
Kidney
Urine
Brain
Cerebro-spinal fluid

\begin{tabular}{rrr}
\multicolumn{1}{r}{$\begin{array}{r}10^{-3} \times \text { no. of organisns } / \mathrm{ml} \text {, in calf: } \\
\text { A }\end{array}$} & \multicolumn{1}{c}{ B } \\
4000 & 1000 & 4000 \\
400 & 1000 & 40000 \\
100000 & 150000 & 300000 \\
200000 & 300000 & 3000000 \\
5000000 & 1000000 & 5000000 \\
10000 & 80 & 70 \\
7000 & 800 & 1000 \\
10000 & 1500 & 500 \\
7000 & 1500 & 600 \\
20000 & 60 & 50 \\
50000 & 100 & 30 \\
300 & 8 & 1 \\
5000 & 500 & 200 \\
1500 & 200 & 700 \\
1500 & 80 & 200 \\
200 & 0 & 25000 \\
100000 & 9000 & 1000 \\
I & 0 & 100000 \\
5000 & 100 & 20 \\
700 & 25 & 10
\end{tabular}

peritoneal washings were $\left(10^{-6} \times\right.$ viable counts $/ \mathrm{ml}$, with ranges in parentheses): blood, 250 ( 3 to 500); peritoneal washings, 50 (6 to 150). The corresponding results for $\mathrm{ColV}^{-}$ organisms were: blood, $0.0001(0.00001$ to 0.01$)$; peritoneal washings, $0.004(0.0005$ to $0.015)$.

The pathogenicity for calves of $\mathrm{ColV}^{+}$and $\mathrm{ColV}^{-}$forms of invasive strains of

E. coli; their concentrations in the tissues of infected calves

Two colostrum-deprived calves inoculated orally with mixtures of B1 $88 \mathrm{ColV}^{-}$and $c o l \mathrm{~V}^{\mathrm{r}}$ organisms appeared normal $24 \mathrm{~h}$ later when one of them was killed. The other was killed at $48 \mathrm{~h}$, by which time it had become moderately unwell. By contrast, one of two calves infected with the same dose of $\mathrm{B} 188 \mathrm{ColV}^{+}$organisms was found dead $24 \mathrm{~h}$ later and the other was collapsed and near to death. Higher concentrations of organisms were present in the tissues of the latter calf than in the corresponding tissues of the two calves given $\mathrm{ColV}^{-}$and $\mathrm{col}^{\mathrm{V}} \mathrm{V}^{\mathrm{r}}$ organisms (Table 2), this difference being most apparent in the blood, and least apparent in organs such as the liver and spleen which by virtue of their high content of reticulo-endothelial cells constitute the main defence mechanism of the body against invading bacteria. The main difference between the two calves given the ColV $\mathrm{V}^{-}$and $\mathrm{col}^{\mathrm{r}}$ forms was the high concentrations of organisms in the bile and urine of the calf killed at $48 \mathrm{~h}$; the ratio of $\mathrm{ColV}^{-}$to $\operatorname{col} \mathrm{V}^{\mathrm{r}}$ organisms in all the materials examined from these two calves was approximately the same as their ratio, 3 to I, in the inoculum.

Isolates were examined from 12 colostrum-deprived calves infected orally with mixtures of $\mathrm{ColV}^{-}$and $\mathrm{ColV}^{-}$organisms of BI88 or of three other invasive strains (Table 3 and Fig. I) 


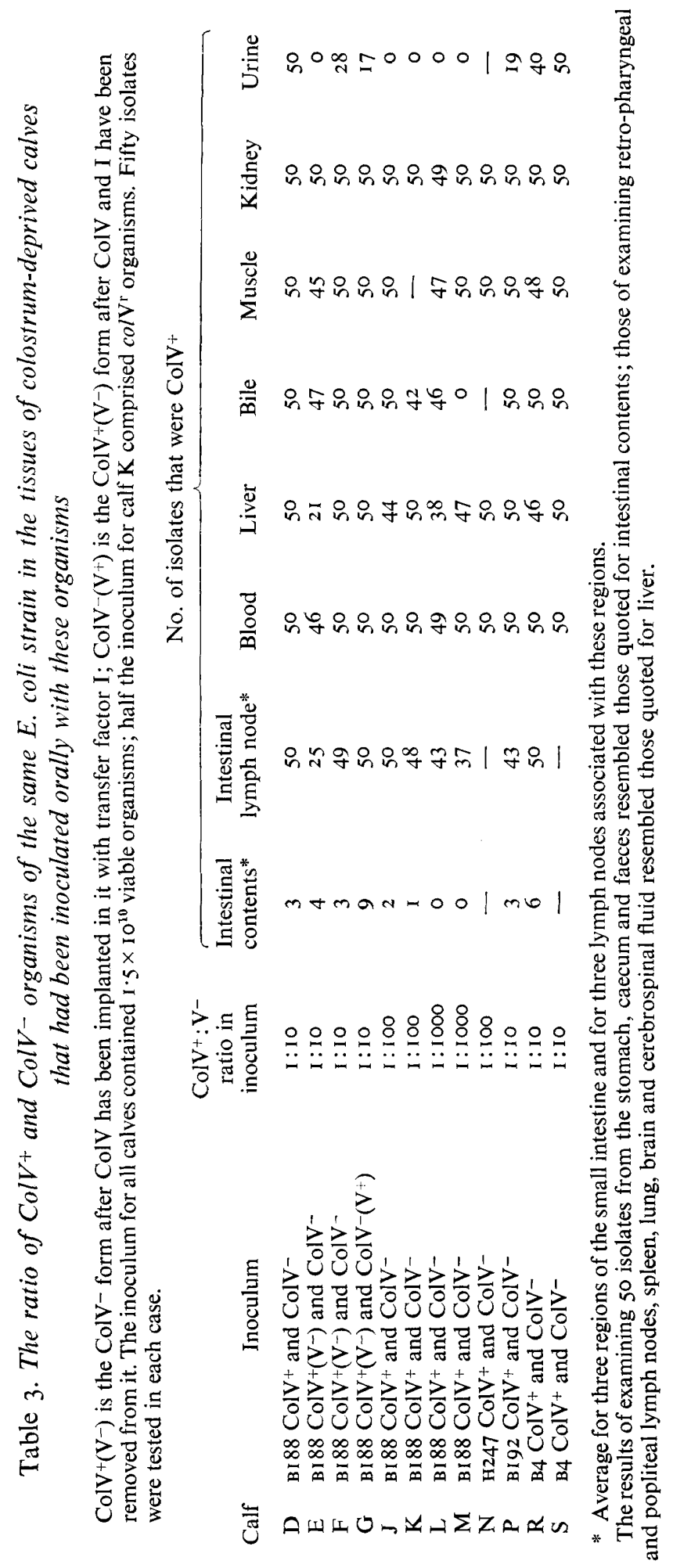




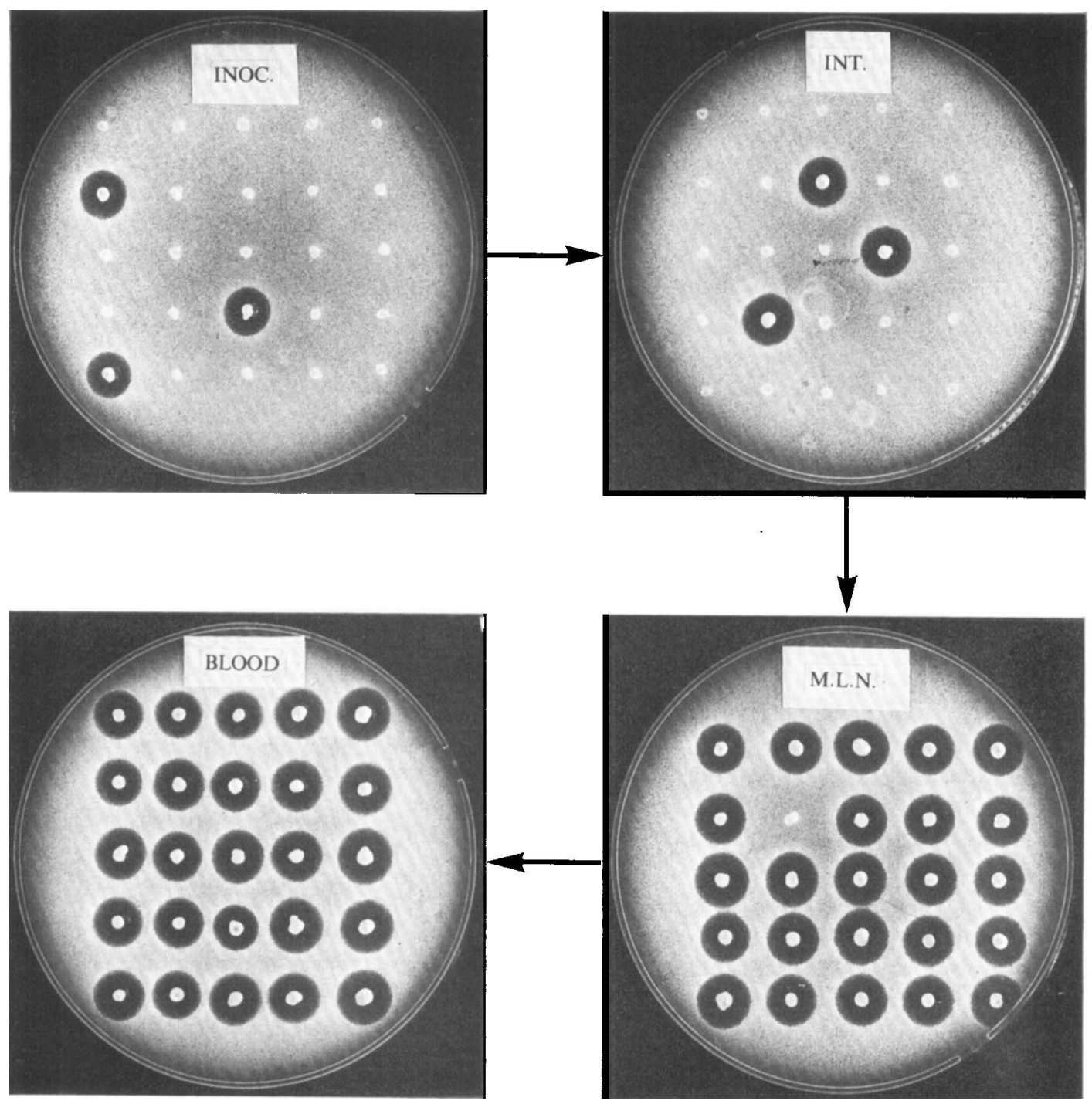

Fig. 1. Colicine tests on $E$. coli isolates from a colostrum-deprived calf that had been inoculated orally with ColV ${ }^{+}$and ColV ${ }^{-}$organisms of $E$. coli $\mathrm{BI} 88$ in a ratio of $\mathrm{I}: 10$. Small portions of $E$. coli colonies cultured from the inoculum (INOC.), the intestinal contents (INT.), a mesenteric lymph node (M.L.N.) and the blood were placed on the surfaces of the plates of nutrient agar after they had been spread with a lawn of $E$. coli $\mathrm{K} 12$. Magnification $\times 0.8$.

and killed when near to death. The ratios of $\mathrm{ColV}^{+}$to $\mathrm{ColV}^{-}$organisms in the contents of different regions of the alimentary tract were similar to that in the inoculum; in the lymph nodes, however, blood, liver, spleen, lung, muscle, kidney, brain and cerebro-spinal fluid $\mathrm{ColV}^{+}$organisms greatly outnumbered the ColV- ones. The concentrations of organisms in the different materials examined from these calves resembled those for calf A quoted in Table 2 except that high concentrations were found in the urine and bile of some of these calves. ColV ${ }^{+}$organisms dominated the isolates from the tissues of the calves infected with 
BI88 even when their numbers in the inoculum were I000 times fewer than those of the $\mathrm{ColV}^{-}$ones and when the inoculum contained $c o l \mathrm{~V}^{\mathrm{r}}$ organisms in addition to $\mathrm{ColV}^{+}$and $\mathrm{ColV}^{-}$ones; the few non-colicine-producing isolates from the calf given these three forms of BI 88 (calf $\mathrm{K}$ ) consisted of approximately the same number of $\mathrm{ColV}^{-}$and $c o / \mathrm{V}^{\mathrm{r}}$ forms. The dominance of ColV+ isolates also applied in the case of the calves given BI92 and B4 (calves $\mathrm{P}, \mathrm{R}$ and $\mathrm{S}$ ), strains whose $\mathrm{ColV}^{-}$forms were completely insusceptible to colicine $\mathrm{V}$; those of BI 88 and $\mathrm{H} 247$ were moderately susceptible. In contrast to the results for the tissues, most of the isolates from the urine of six calves and the bile of one calf - fluids remote from the defence mechanisms of the body - were ColV ${ }^{-}$. Similar results to those quoted in Table 3 were obtained by infecting a colostrum-deprived calf intravenously instead of orally with $\mathrm{IO}^{5}$ viable organisms of a mixture of $\mathrm{ColV}^{+}, \mathrm{ColV}^{-}$and $\mathrm{col} \mathrm{V}^{\mathrm{r}}$ forms of $\mathrm{BI} 88$ in the ratio I : 4.5:4.5. Apart from two isolates, one of which was ColV- and the other col $\mathrm{V}^{\mathrm{r}}$, all of the 350 isolates from the blood, kidney, spleen, muscle, mesenteric lymph node, bile and urine were $\mathrm{ColV}^{+}$. In contrast with the results of all the ColV experiments, the ratio of $\mathrm{ColE}^{+}$ to $\mathrm{ColE}^{-}$organisms amongst isolates made from the alimentary contents and tissues of a colostrum-deprived calf $26 \mathrm{~h}$ after it had been infected orally with $\mathrm{BI} 88 \mathrm{ColV}^{-} \mathrm{ColE}^{+}$and $\mathrm{ColV}^{-}$organisms was the same as in the inoculum, I to Io.

Blood samples were taken from some of the calves referred to in Table 3 on several occasions before they were killed. $\mathrm{ColV}^{+}$organisms became dominant amongst the isolates from these samples at a time when they contained only low concentrations of organisms. For example, of 50 isolates obtained from calf $\mathrm{M}$ at 20, 24, 30 and $40 \mathrm{~h}$, the numbers that were $\mathrm{ColV}^{+}$were I, 3, 30 and 50. At these times, the numbers of viable organisms $/ \mathrm{ml}$ of blood $\left(\times 10^{-4}\right)$ were $8,7,2$ and 20 , respectively.

The numbers of $\mathrm{ColV}^{+}, \mathrm{ColV}^{-}$and col $\mathrm{V}^{\mathrm{r}}$ organisms in the blood of a colostrum-deprived calf were estimated on several occasions during the $9 \mathrm{~h}$ period between the time it was inoculated intravenously with these organisms and the time it was killed when near to death (Table 4). Similar estimates were made on a sample of blood removed 3 min after inoculation, on two pre-inoculation serum samples (one raw and one heated to destroy complement), and on broth; the three forms of BI 88 were added to the serum samples and the broth in the same proportions as they were given to the calf. All the samples and the broth were held at $37^{\circ} \mathrm{C}$. Neither the concentrations of organisms in the circulating blood of the calf or the ratio of $\mathrm{ColV}^{+}, \mathrm{ColV}^{-}$and $c o l \mathrm{~V}^{\mathrm{r}}$ organisms amongst the isolates changed during the first $5 \mathrm{~h}$. The concentrations of organisms then increased, as did the proportion of isolates that were $\mathrm{ColV}^{+}$; the proportion of $\mathrm{ColV}^{-}$to $\operatorname{col} \mathrm{V}^{\mathrm{r}}$ isolates remained approximately the same. The inoculated bacteria multiplied rapidly in the blood and serum maintained at $37^{\circ} \mathrm{C}$. The proportion of $\mathrm{ColV}^{-}$organisms amongst the isolates from the blood and serum samples after 4 to $5 \mathrm{~h}$ was very low; the proportion of col $\mathrm{V}^{\mathrm{r}}$ organisms amongst the isolates from both serum samples showed little alteration during the whole observation period but after $6 \mathrm{~h}$ the proportion of these organisms in the blood sample decreased slightly. The proportion of $\mathrm{ColV}^{+}, \mathrm{ColV}^{-}$and colvr organisms in the broth, which was known to be unsuitable for colicine $\mathrm{V}$ production, remained constant throughout. The colicine $\mathrm{V}$ titre of the serum of the blood taken from the calf at the end of the experiment was $\mathrm{I}$ in I; that of the incubated blood and serum samples was in the region of $\mathrm{I}$ in 8 ; no colicine $\mathrm{V}$ was detected in the broth culture. A specimen of serum obtained from the calf at the end of the experiment was heated to $60{ }^{\circ} \mathrm{C}$ for $\mathrm{I} \mathrm{h}$ to destroy the bacteria it contained, held at $37{ }^{\circ} \mathrm{C}$ and inoculated, at $10^{5}$ viable organisms $/ \mathrm{ml}$, with a mixture of equal numbers of $\mathrm{ColV}^{-}$and $\mathrm{col} \mathrm{V}^{\mathrm{r}}$ organisms of BI 88 growing exponentially in the serum of another colostrum-deprived calf. The ratio of $\mathrm{ColV}^{-}$to $\mathrm{col} \mathrm{V}^{\mathrm{r}}$ organisms was the same at 0.5 and 


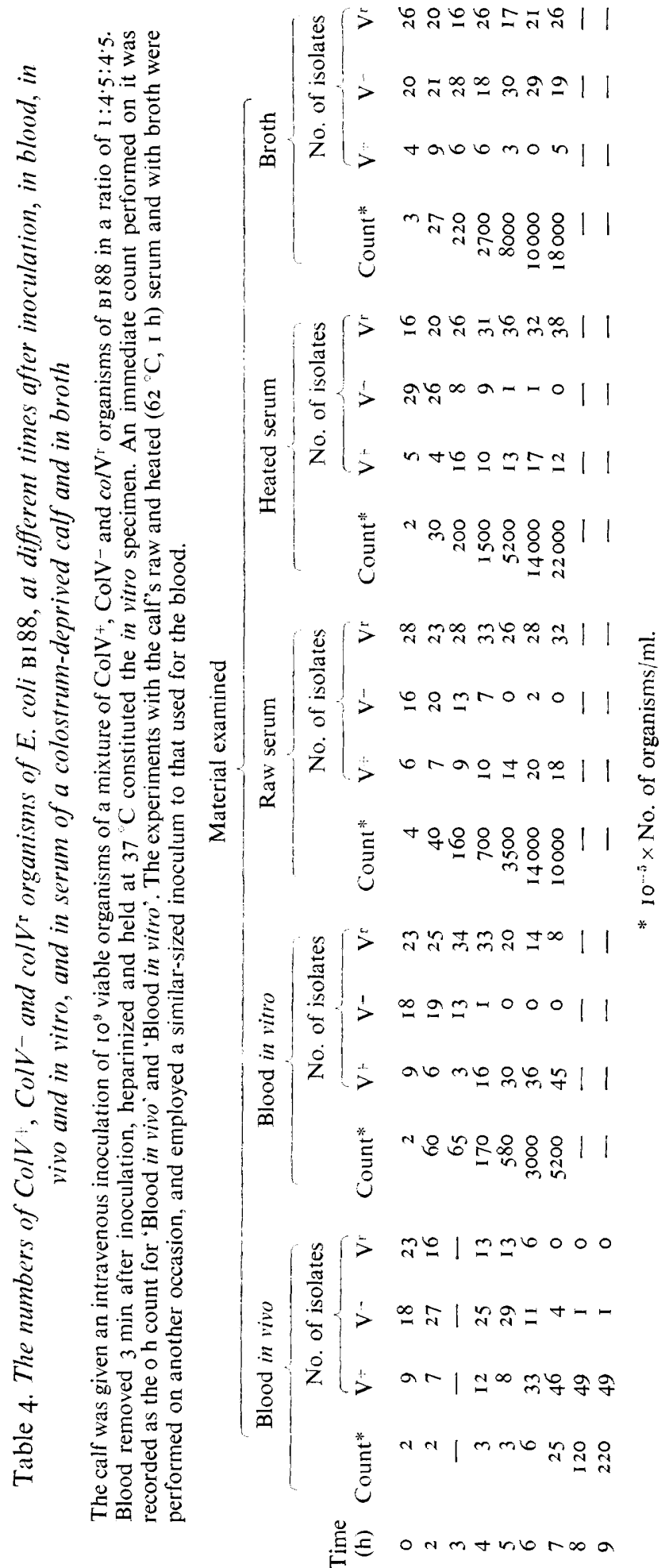


Table 5. The ratio of $\mathrm{ColV}^{+}, \mathrm{ColV}^{-}$and colV organisms of E. coli $\mathrm{BI} 88$ in the faeces of two human beings after they had consumed mixtures of these organisms

In expt $\mathrm{I}$ the human beings consumed $\mathrm{IO}^{10}$ viable $\mathrm{ColV}^{+}$and $\mathrm{ColV}-$ organisms and in expt 2 a similar dose of $\mathrm{ColV}^{+}, \mathrm{ColV}^{-}$and $\mathrm{col} \mathrm{V}^{r}$ organisms; $\mathrm{I}$ in $\mathrm{I} 0$ of the organisms consumed in both experiments were $\mathrm{ColV}^{+}$. The organisms consumed by human being No. I were nal-r spc-r mutants and those consumed by human being No. 2 were nal-r str-r mutants. They were recovered from the faeces of the human beings by culturing on MacConkey's medium containing the two antibiotics to which they were resistant. Fifty isolates were tested in each case.

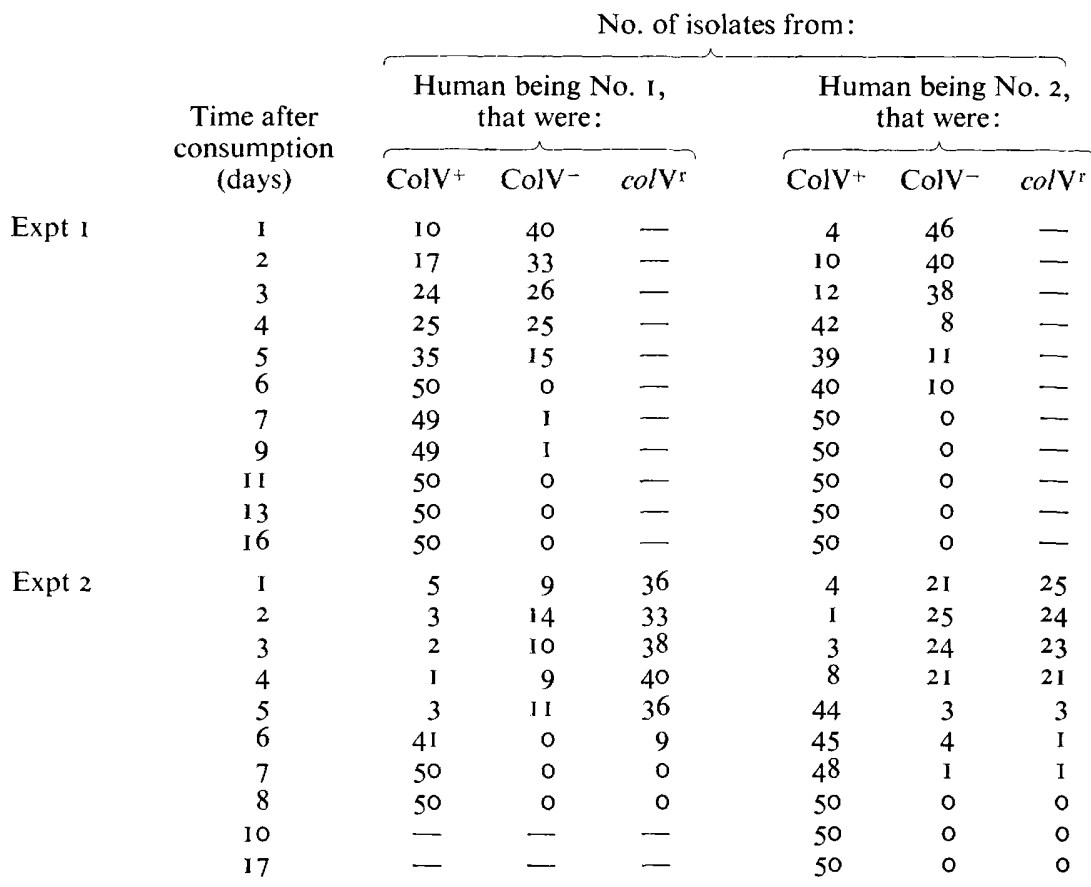

$\mathrm{I} \mathrm{h}$ as at $\mathrm{o} \mathrm{h}$, but at $\mathrm{I} \cdot 5 \mathrm{~h}$ the proportion of $c o l \mathrm{~V}^{\mathrm{r}}$ organisms had increased slightly. When mixtures of $\mathrm{ColV}^{+}$and $\mathrm{ColV}^{-}$organisms of $\mathrm{FI} 85$, an invasive strain whose $\mathrm{ColV}^{-}$- form was completely insusceptible to colicine $\mathrm{V}$, were incubated in the serum of a colostrum-deprived calf, the $\mathrm{ColV}^{+}: \mathrm{ColV}^{-}$ratio was the same at $24 \mathrm{~h}$ as at $\mathrm{o} \mathrm{h}$.

The comparative survivability of $\mathrm{ColV}^{+}$and $\mathrm{ColV}^{-}$organisms of the same strain in the alimentary tract

$\mathrm{ColV}^{+}$forms gradually became more dominant amongst the $\mathrm{BI} 88$ isolates from the faeces of two human beings who had consumed mixtures of $\mathrm{ColV}^{+}$and $\mathrm{ColV}^{-}$or of $\mathrm{ColV}^{+}$, $\mathrm{ColV}^{-}$and $c o l \mathrm{~V}^{\mathrm{r}}$ organisms of this strain, until eventually they were the only form isolated, a situation that persisted until B188 organisms disappeared from the faeces (Table 5). After each occasion that they were taken by human being No. I, BI 88 organisms formed the major component of his $E$. coli faecal flora for several weeks. In human being No. 2 they formed the major component for only a few days although they persisted in his faeces for several weeks. At the end of one experiment, none of the $50 \mathrm{ColV}^{+}$isolates obtained from one faecal specimen of human being No. 2 were found to be able to transmit ColV, an indication that none of them were really ColV-forms of B 88 that had acquired ColV plasmids from other 
E. coli that were inhabiting the alimentary tract (the ColV of BI $88 \mathrm{ColV}^{+}$is non-transmissible). In another experiment human being No. I took a mixture of equal quantities of $\mathrm{BI} 88 \mathrm{ColV}^{-}$and $\mathrm{col}^{\mathrm{r}} \mathrm{V}^{\mathrm{r}}$ organisms. In all subsequent faecal examinations they were found in approximately this proportion. When both human beings took, in a ratio of $1: \mathrm{Io}, \mathrm{ColV}^{+}$ and $\mathrm{ColV}^{-}$organisms of $\mathrm{B} 192$ (a strain whose ColV is non-transmissible and whose ColVform is completely resistant to colicine $V$ ), the results were substantially the same as thoseobtained following the consumption of the ColV and ColV-forms of B 188 . This state of affairs continued until the end of the observation period.

In a further experiment, the two human beings consumed $10^{10}$ viable organisms consisting of $\mathrm{ColE}^{+}$and $\mathrm{ColE}^{-}$forms of a nal-r str-r mutant of strain B $88 \mathrm{ColV}^{-}$in a ratio of $\mathrm{I}: \mathrm{IO}$. ColE ${ }^{+}$organisms did not become dominant amongst the BI 88 isolates obtained subsequently from the faeces by culturing on MacConkey's agar containing sodium nalidixate and streptomycin. In one individual, repeated sampling showed that the percentages of faecal $\mathrm{B} 188$ organisms that proved to be $\mathrm{ColE}^{+}$ranged from 4 to 42 (mean 18 ) over the first 6 days, and had fallen to nil by the 9 th day. In the second individual, the corresponding figures were 6 to 72 (mean 21 ) over the first 12 days and had fallen to nil by the 13 th day.

The ratios of the numbers of $E$. coli $\mathrm{F} 65$ organisms to the numbers of the general E. coli organisms, in the caecal contents of ten chickens 6 days after they had been inoculated orally with $5 \times 10^{9}$ viable organisms of a ColV $\%$ form of a nal-r spc-r mutant of $\mathrm{F} 65$, were I:I, I:5, I:5, 1:10, I:I0, I:20, I:50, 1:50, 1:100 and $1: 500$; in ten given the ColV-form instead of the ColV $\mathrm{C}^{+}$form the ratios were $1: 300$, I:I000, I:I000, I:1000, I:3000, I:3000, $\mathrm{I}: 30000, \mathrm{I}: 50000, \mathrm{I}: 200000$ and $\mathrm{I}:>1000000$. The concentration of the general E. coli in the caeca of the chickens in both groups was similar, the median concentration for each group being $50 \times 10^{6}$ viable organisms $/ \mathrm{ml}$.

\section{DISCUSSION}

The elimination of Colv in various ways from human, bovine, ovine, and avian E. coli strains belonging to a number of serological types was always accompanied by a distinct decrease in pathogenicity. Furthermore, the pathogenicity of ColV- forms could be increased, usually to that of the Colv ${ }^{+}$forms from which they were derived, by implanting other Colv plasmids in them. These observations are in accord with earlier ones made on essentially non-pathogenic strains of $E$. coli, such as K I2, in which different ColV plasmids had been implanted. However, as the present ones were made on invasive strains employing inoculation methods that gave rise to a disease in chickens and colostrum-deprived calves indistinguishable ftom that which these strains cause under natural conditions, they suggest even more strongly that ColV is an important pathogenic character of E. coli. It is particularly significant in this respect that a high proportion of the invasive strains examined produced colicine V. Of those that did not produce it, some may have possessed a ColV determinant when originally isolated from a disease process but may have lost it during the several years they were maintained in the laboratory before their ColV status was determined; ColV was shown to be unstable in some of our stock cultures. Although the genes determining colicine $\mathrm{V}$ production could not be transmitted from some of the invasive strains, even after transfer factors $F$ and $I$ were established in the strains, they were easily eliminated during sodium lauryl sulphate treatment, which strongly suggested that they were located in plasmids. For this reason it still cannot be concluded that colicine $\mathrm{V}$ or some related substance determined by the ColV gene is responsible for the increased pathogenicity, since it is always possible that other genes present in these plasmids are really responsible for this increased pathogenicity. Whatever substance is implicated it must 
function by remaining intimately associated with the bacteria that form it, to provide increased protection against the defence mechanisms of the body. It does not function by reducing the effectiveness of the defence mechanisms in the manner of an exotoxin. If it did so, then in the chickens and calves used in the mixed infection experiments the ColVorganisms would have proliferated to the same extent as the $\mathrm{ColV}^{+}$ones, whereas they did not appear to proliferate to any greater extent than when they were used alone.

The mixed infections in the colostrum-deprived calves provided the best illustration of the differing in vivo behaviour of $\mathrm{ColV}^{+}$and $\mathrm{ColV}^{-}$forms. During the $\mathrm{I}$ to 2 days that the calves survived, the ratio of the two forms in the alimentary tract remained the same as in the inoculum. In the early stages of invasion, the ColV-forms predominated in the blood but to a lesser extent than they did in the inoculum. Later, while the blood concentrations were still low, the ratio altered in favour of the ColV+ organisms. These then proliferated and when the calves were killed they dominated the isolates from the blood and tissues. The frequent predominance of ColV- organisms in the urine samples and, occasionally, in the bile samples examined at this time was probably the consequence of these fluids becoming infected in the early stages of infection when the $\mathrm{ColV}^{-}$organisms were still more numerous in the blood than the ColV ${ }^{+}$ones. Their continued dominance can be explained by the fact that, being away from the defence mechanisms of the body, they were no longer competing unequally with the $\mathrm{ColV}^{+}$ones.

Braude \& Siemienski (I965) found that after subcutaneous injection of colicine $V$ the sera of mice became strongly bactericidal for colicine V-sensitive $E$. coli. Concentrations of colicine $\mathrm{V}$ bactericidal for $E$. coli $\mathrm{KI} 2$ were found in the present studies in blood samples taken from infected calves when they were near to death. However, the concentrations were not sufficiently high to influence significantly the multiplication of the less colicine Vsusceptible BI $88 \mathrm{ColV}^{-}$organisms. It therefore seemed unlikely that colicine $\mathrm{V}$ production in vivo had influenced the $\mathrm{B} 188 \mathrm{ColV}^{-}: \mathrm{ColV}^{+}$ratio in the calves inoculated with mixtures of these organisms, particularly since the $\mathrm{ColV}^{+}$organisms assumed their dominant role in the blood of these calves at a time when their concentrations were low, approximately onehundredth of that present at death. Furthermore, col $\mathrm{V}^{\mathrm{r}}$ organisms survived no better than $\mathrm{ColV}^{-}$ones in calves infected with both these forms of BI88 in addition to $\mathrm{ColV}^{+}$forms. The degree of $\mathrm{ColV}^{+}$dominance found in calves infected with mixtures of $\mathrm{ColV}^{+}$and $\mathrm{ColV}^{-}$forms of strains whose $\mathrm{ColV}^{-}$forms were completely colicine V-resistant, too, resembled that observed with в I 88 . The $c o / V^{r}$ form of в 88 appeared little more susceptible to complement than did the ColV ${ }^{+}$form, in that its rate of multiplication in raw and heated samples of colostrum-deprived calf serum resembled that of the $\mathrm{ColV}^{+}$form. The ColVform with which these samples were also inoculated disappeared fairly rapidly; this clearly was due to the colicine $\mathrm{V}$ produced by the ColV ${ }^{+}$organisms. Chicken blood also proved a good medium for the in vitro production of colicine $\mathrm{V}$, though on occasion the colicine content of chicken and of calf blood cultures was low, possibly due to the antagonizing effect of endotoxin (Braude \& Siemienski, 1965). This may explain our failure to demonstrate colicine $\mathrm{V}$ in the inoculation site of the dead chickens that had had mixtures of $\mathrm{ColV}^{+}$, $\mathrm{ColV}^{-}$and $c o l \mathrm{~V}^{\mathrm{r}} \mathrm{B} 88$ organisms injected into the same muscle; our failure to isolate ColVorganisms, but not col $\mathrm{V}^{\mathrm{r}}$ organisms, from the site strongly suggested that the very high concentrations of $\mathrm{ColV}^{+}$organisms present - some 1000 times higher than that found in the blood or tissues of dying calves - must at some time have produced sufficient colicine $\mathrm{V}$ adversely to influence the survival of the BI $88 \mathrm{ColV}^{-}$organisms.

The experiments in chickens and human beings revealed that ColV confers on organisms an increased ability to survive in the alimentary tract in addition to the tissues. Support for 
this conclusion with regard to the experiments with В 88 and $\mathrm{B} 192$ in human beings derives from the following observations: (i) As far as can be determined the ColV ${ }^{+}$and $\mathrm{ColV}^{-}$ forms of в 88 and of в 92 differ only in the possession of a ColV plasmid. (ii) The ColV of both strains is non-transmissible, which eliminates the possibility of ColV transfer from the ColV to the ColV- organisms occurring in the alimentary tract. (iii) None of 50 BI 88 ColV ${ }^{+}$isolates from human being No. 2 at the end of one experiment could transmit their ability to produce colicine, indicating they were not B $88 \mathrm{ColV}^{-}$organisms that had acquired Colv from any $\mathrm{ColV}^{+} E$. coli other than $\mathrm{BI} 88$ that might have been present in his alimentary tract. (iv) In the experiments in which mixtures of Br $88 \mathrm{ColV}^{+}, \mathrm{ColV}^{-}$and col $\mathrm{V}^{\mathrm{r}}$ organisms were ingested, the $\mathrm{ColV}^{-}$organisms survived as long as the col $\mathrm{V}^{\mathrm{r}}$ ones, indicating that colicine $\mathrm{V}$ was not providing any selection pressure in the alimentary tract as far as Bı 88 organisms were concerned; ColV- and $c^{-} / \mathrm{V}^{\mathrm{r}}$ organisms survived equally well in the absence of ColV $\div$ ones. Furthermore, colicine $\mathrm{V}$ could not influence the B 192 experiments because the ColV- form of this strain was resistant to colicine $V$, and its bactericidal effect also did not appear to play a part in the chicken experiments, in that the general $E$. coli population of the caeca of the chickens given the Colv form of 565 was no lower than that of the caeca of the chickens given the ColV - form.

After taking mixtures of different forms of the same E. coli strain, several days always elapsed before the ColV ${ }^{+}$form dominated the other forms in the alimentary tract of the human beings, indicating that the survival value conferred by possession of Colv, although definite, was not intense. Its expression, therefore, may sometimes be masked in experiments in which wild-type strains that do or do not produce colicine $V$ are compared, because they can differ in many respects other than in ability to produce colicine $\mathrm{V}$; this may explain why such experiments have not yielded unequivocal results.

The fact that the $\mathrm{ColE}^{+}$form of $E$. coli $\mathrm{BI} 88 \mathrm{ColV}^{-}$did not survive better than the ColEform in the alimentary tract of the two human beings indicates that all colicine determinants do not confer increased survival on $E$. coli possessing them. The ColE $E^{+}$form also was no more pathogenic for chickens, mice and calves than the $\mathrm{ColE}^{-}$form, and those colicines (other than V) tested by Smith (1974) did not confer increased pathogenicity on E. coli KI2. These findings, together with those made on ColV, may explain, at least in part, why colicine $\mathrm{V}$ is the most common colicine produced by $E$. coli (Wilson \& Miles, I964).

We are grateful to Mrs Frances Richards for her capable technical help. Our thanks are also due to Dr P. M. Biggs, Miss Doreen Cooper, Mr R. Sampson and Mrs Margaret Webster for assistance in a variety of ways.

\section{REFERENCES}

Aschaffenburg, R. (1949). The nutritive value of colostrum for the calf. 1II. Changes in the serum protein of the new born calf following the ingestion of small quantities of the non-fatty fraction. British Journal of Nutrition 3, 200-204.

Bouanchaud, D. H., Scavizzi, M. R. \& Chablert, Y. A. (1968). Elimination by ethidium bromide of antibiotic resistance in Enterobacteriaceae and staphylococci. Journal of General Microbiology 54, $417-425$.

Braude, A. I. \& Siemienski, J. S. (I965). The inlluence of bacteriocins on resistance to infection by Gramnegative bacteria. I. The effect of colicin on the bactericidal power of the blood. Journal of Clinical Investigation 44, 849-859.

Hardy, K. G., Meynell, G. G., Dowman, J. E. \& Spratt, B. G. (1973). Two major groups of colicin factors; their evolutionary significance. Molecular and General Genetics 125, 217-230.

HAYES, W. (I953). Observations on a transmissible agent determining sexual differentiation in Bacterium coli. Journal of General Microbiology 8, 72-88. 
Hirota, Y. (1960). The effect of acridine dyes on mating type factors in Escherichia coli. Proceedings of the National Academy of Sciences of the United States of America 46, 57-64.

Lederberg, J., Cavalli, L. L. \& LederberG, E. M. (I952). Sex compatibility in E. coli. Genetics 37, 720.

SMITH, H. WILliams (I974). A search for transmissible pathogenic characters in invasive strains of Escherichia coli: the discovery of a plasmid-controlled toxin and a plasmid-controlled lethal character closely associated, or identical, with colicine V. Journal of General Microbiology 83, 95-I I I.

Tomoeda, M., Inuzuka, M., Kuba, N. \& NaKama, S. (1968). Effective elimination of drug resistance and sex factors in Escherichia coli by sodium dodecyl sulphate. Journal of Bacteriology 95, 1078.

Wilson, G. S. \& Miles, A. A. (I964). Topley and Wilson's Principles of Bacteriology and Immunity, 5th edn, p. 461. London: Edward Arnold. 